Ann. Biol. anim. Bioch. Biophys., I973, 13 (I), 5 I-73.

\title{
INFLUENCE DE L'HYPOPHYSECTOMIE ET DE TRAITEMENTS \\ A L'HORMONE SOMATOTROPE BOVINE SUR LA CROISSANCE RELATIVE DE L'AGNEAU
}

\author{
A. VÉZINHET \\ avec la collaboration technique de E. Bouthier et Thérèse ChERY \\ Station de Physiologie animale, I. N.R.A., \\ École nationale supérieure agronomique, \\ Place Viala, 34060 Montpellier Cedex
}

\section{RÉSUMÉ}

Une étude de la croissance relative révèle que l'hypophysectomie pratiquée chez des agneaux de 25,50 et Ioo jours, arrête le développement de la masse musculaire tandis qu'un léger accroissement du tissu osseux se poursuit. Le tissu adipeux continue à croître sans être affecté pour les animaux opérés à 25 et 50 jours, alors que chez ceux opérés à roo jours, la croissance de la masse adipeuse est stimulée.

L'hormone somatotrope bovine (BGH) injectée trois fois par semaine à la dose de $3 \mathrm{mg}$ par $\mathrm{kg}$ de poids vif stimule la croissance musculaire et osseuse et réduit considérablement les réserves en tissus adipeux.

Une étude réalisée sur les glandes endocrines montre, en outre, que l'hypophysectomie induit une régression pondérale des gonades, des surrénales et de la thyroìde. Le traitement chronique à la $\mathrm{BGH}$ ne permet pas d'annihiler les effets constatés sur les gonades et les surrénales. La thyroïde réagit différemment.

Enfin, le foie se comporte, vis-à-vis de l'hypophysectomie et du traitement à la BGH, de façon très semblable à l'organisme entier.

\section{INTRODUCTION}

L'hypophysectomie réalisée précocement entraîne chez 1'Agneau un ralentissement immédiat et durable de la croissance pondérale (VÉzInHET, Ig68 a). Ce ralentissement très marqué peut être en partie corrigé par un traitement chronique à 
1'hormone somatotrope bovine (BGH) (VÉzINHE'T et DAUZIER, I970). I1 n'existe pas, à notre connaissance, de données concernant l'influence d'un tel traitement chez l'Agneau et notamment sur les proportions relatives des différents tissus, ainsi que sur l'évolution pondérale des principales glandes endocrines et de certains organes.

Dans un travail ancien, LEE et AYRES (I936) ont montré que l'hypophysectomie se traduit chez le Rat par d'importants remaniements de la composition corporelle. La teneur en azote du corps est particulièrement réduite ; les dépôts adipeux sont, par contre, beaucoup moins affectés. Des injections répétées de GH corrigent en grande partie le déficit d'anabolisme protéique constaté après hypophysectomie, tandis que les lipides de réserve sont considérablement réduits (LI et EvaNs, I948; de BoDo et AITSZULIER, I957). Dans le cadre de cette étude qui se limite aux seuls aspects descriptifs de la croissance relative, nous n'envisagerons pas les modalités d'action de l'hormone somatotrope qui ont donné lieu à de très nombreux travaux. Nous nous contenterons de rappeler toujours à partir de travaux anciens que la GH favorise chez le Rat une importante rétention azotée (SzEGo et WHITE, I949; RUSSEL, I955 ; KNOBIL et GREEP, I959) et provoque une mobilisation des lipides de réserve (RABEN et HOLLENBERG, I958; ENGEL et al., I958). En ce qui concerne les glandes endocrines qui seront envisagées ici, et dont le fonctionnement est placé sous un contrôle hypo physaire, plus ou moins étroit, on sait qu'elles subissent après hypophysectomie des régressions pondérales. Ces observations ont été réalisées essentiellement chez le Rat.

\section{MATÉRIEI E'T MÉTHODES}

Ce travail a porté sur 75 agneaux Mérinos d'Arles issus du troupeau élevé au laboratoire. 45 agneaux (22 mâles et 23 femelles) ont subi une hypophysectomie ou un simulacre d'opération à 25,50 ou roo jours; il ont été abattus, après que certains aient reçu un traitement chronique à la BGH, aux âges respectifs de Ioo, I 50 et 250 jours. Le détail des groupes expérimentaux est donné au tableau r. En outre, 30 agneaux normaux ont été abattus et disséqués aux âges de 25 jours ( 4 mâles et 4 femelles), 5o jours ( 4 mâles et 4 femelles), roo jours ( 3 mâles et 3 femelles), I 50 jours ( 2 mâles et 2 femelles) et 250 jours ( 2 mâles et 2 femelles).

Les dissections de ces animaux normaux ayant été effectuées au début et à la fin de chaque période étudiée, les valeurs obtenues ont permis d'avoir une image de l'évolution normale des différents paramètres étudiés et d'estimer l'influence de l'hypophysectomie, du traitement à la $\mathrm{BGH}$ et du choc opératoire chez les sujets dits pseudo-hypophysectomisés qui ont subi un simulacre d'opération.

Tous ces animaux étudiés ont été soumis à un régime ad libitum à base de concentré et de foin et avaient un accès libre à la nourriture.

L'hormone somatotrope bovine utilisée est une hormone Byla lot or-67 activité x,I UI par mg. La liste des contaminants est la suivante : ACTH o, 00025 UI par $\mathrm{mg}$, ICSH inférieur à 0,4 UI par mg, FSH néant, Prolactine o,o6 UI par mg, Ocytocine o,000 4 UI par mg, TSH non titré. Les animaux traités à la BGH ont reçu l'hormone dissoute extemporanément, par voie intramusculaire. Les injections ont eu lieu trois fois par semaine à la dose de $3 \mathrm{mg}$ par $\mathrm{kg}$ de poids vif (VEzinhet et Dauzier, r97o). La survie des animaux a été assurée par un traitement à la cortisone dans les conditions suivantes :

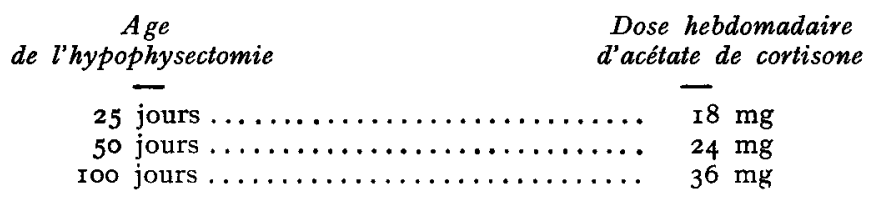


Après l'abattage, la carcasse a été séparée en deux suivant un plan médio-sagittal. Une demicarcasse a été ensuite entièrement disséquée suivant la méthode décrite par BÉnÉvENr, I968. L'estimation des tissus musculaires, osseux et adipeux qui seront étudiés dans ce texte, a été faite de la façon suivante.

Pour le tissu musculaire : tous les muscles de la demi-carcasse obtenus individuellement ont été additionnés et multipliés par 2. Les muscles de la tête et les intercostaux n'ont pas été pris en compte en raison de la difficulté à les obtenir de façon reproductible. Pour le tissu osseux

TABLEAU I

Protncole expérimental

\begin{tabular}{|c|c|c|}
\hline $\begin{array}{l}\text { Désignation } \\
\text { des lots }\end{array}$ & $\begin{array}{l}\text { Lots expérimentaux } \\
\text { (nombre d'animaux et sexe) }\end{array}$ & Nature du traitement \\
\hline Lot 1 & $\begin{array}{c}\text { Agneaux hypophysectomisés à } 25 \text { jours } \\
2 \text { mâles } \\
2 \text { femelles }\end{array}$ & $\begin{array}{l}\text { Sans traitement } \\
\text { Abattage à } 100 \text { jours }\end{array}$ \\
\hline Lot 2 & $\begin{array}{l}\text { Agneaux ayant subi } \\
\text { un simulacre d'opération à } 25 \text { jours } \\
3 \text { mâles } \\
2 \text { femelles }\end{array}$ & $\begin{array}{l}\text { Sans traitement, abattage à } 100 \text { jours } \\
\text { Lot témoin des lots } 1 \text { et } 3\end{array}$ \\
\hline Lot 3 & $\begin{array}{c}\text { Agneaux hypophysectomisés à } 25 \text { jours } \\
3 \text { mâles } \\
4 \text { femelles }\end{array}$ & $\begin{array}{l}\text { Traitement à la BGH de } 25 \text { à } 100 \text { jours } \\
\text { Abattage à } 100 \text { jours }\end{array}$ \\
\hline Lot 4 & $\begin{array}{l}\text { Agneaux hypophysectomisés à } 50 \text { jours } \\
4 \text { mâles } \\
5 \text { femelles }\end{array}$ & $\begin{array}{l}\text { Sans traitement } \\
\text { Abattage à } 150 \text { jours }\end{array}$ \\
\hline Lot 5 & $\begin{array}{l}\text { Agneaux ayant subi } \\
\text { un simulacre d'opération à } 50 \text { jours } \\
2 \text { mâles } \\
2 \text { femelles }\end{array}$ & $\begin{array}{l}\text { Sans traitement, abattage à } 150 \text { jours } \\
\text { Lot témoin des lots } 4 \text { et } 6\end{array}$ \\
\hline I.ot 6 & $\begin{array}{c}\text { Agneaux hypophysectomisés à } 50 \text { jours } \\
3 \text { mâles } \\
4 \text { femelles }\end{array}$ & $\begin{array}{c}\text { Traitement à la BGH de } 50 \text { à } 150 \text { jours } \\
\text { Abattage à } 150 \text { jours }\end{array}$ \\
\hline Lot 7 & $\begin{array}{c}\text { Agneaux hypophysectomisés à } 100 \text { jours } \\
3 \text { mâles } \\
2 \text { femelles }\end{array}$ & $\begin{array}{l}\text { Sans traitement } \\
\text { Abattage à } 250 \text { jours }\end{array}$ \\
\hline Lot 8 & $\begin{array}{l}\text { Agneaux ayant subi } \\
\text { un simulacre d'opération à } 100 \text { jours } \\
2 \text { mâles } \\
2 \text { femelles }\end{array}$ & $\begin{array}{l}\text { Sans traitement, abattage à } 250 \text { jour: } \\
\text { Lot témoin du lot } 7\end{array}$ \\
\hline
\end{tabular}

nous avons multiplié par 2 tous les os de la demi carcasse, sauf la colonne vertébrale qui a été supprimée. Il est, en effet, difficile de séparer la carcasse en deux parties suivant un plan strictement médio-sagittal. Enfin le tissu adipeux a été estimé en multipliant par 2 tous les dépôts adipeux (internes, intermusculaires et sous-cutanés) récupérés au cours de la dissection de la demicarcasse. Les glandes endocrines (testicules ou ovaires, surrénales et thyroïde) et le foie, qui seront également étudiés ici, ont été prélevés immédiatement après l'abattage. 
L'analyse des résultats a consisté en une étude de l'évolution pondérale des différentes variables étudiées. La simple comparaison des valeurs absolues entre les animaux traités et les normaux permet d'estimer l'effet des traitements. Cette analyse a été réalisée à partir de l'exploitation des données du tableau 2.

Nous avons, en outre, comparé les vitesses de croissance spécifiques relatives, exprimées par un coefficient d'allométrie $(a)$, pour les différents lots expérimentaux et les agneaux normaux.

La croissance de deux parties $y$ et $x$ d'un organisme, ou d'une partie $(y)$ relativement au tout (x) a été décrite depuis les travaux de HuxLey (I932) et TeIssier (I934) par la relation d'allométrie.

$$
y=b x^{a}
$$

qui sous la forme logarithmique s'écrit

$$
\log y=a \log x+\log b \quad \text { ou } \frac{\mathrm{d} y}{y} / \frac{\mathrm{d} x}{x}=a
$$

En dérivant par rapport au temps dont $y$ et $x$ sont fonction on obtient :

$$
\frac{\mathrm{d} y}{y \mathrm{~d} t} / \frac{\mathrm{d} x}{x \mathrm{~d} t}=a
$$

Pour la période de temps considéré nous estimerons la vitesse spécifique de croissance $\frac{\mathrm{d} y}{y \mathrm{~d} t}$ selon FISHER (I92I) :

$$
\frac{\mathrm{d} y}{y \mathrm{~d} t}=\frac{\mathrm{d}(\log y)}{\mathrm{d} t}=\frac{\left(\log y_{2}\right)-\left(\log y_{1}\right)}{\mathrm{d} t} \quad \text { et } \quad \frac{\mathrm{d} x}{x \mathrm{~d} t}=\frac{d(\log x)}{\mathrm{d} t}=\frac{\left(\log x_{2}\right)-\left(\log x_{1}\right)}{\mathrm{d} t}
$$
métrie.

On utilise le rapport des vitesses spécifiques de croissance pour obtenir le coefficient d'allo-

$$
a=\frac{\left(\log y_{2}\right)-\left(\log y_{1}\right)}{\left(\log x_{2}\right)-\left(\log x_{1}\right)}
$$

Nous avons pris comme variable de référence $(x)$ le poids vif vide (poids vif diminué des poids des contenus du tube digestif et de la vessie). Cette étude d'allométrie permet de juger des modifications apportées par les différents traitements aux vitesses spécifiques relatives de croissance, ceci pour les trois périodes étudiées ( 25 à Ioo jours, 50 à I 50 jours et Ioo à 250 jours).

\section{RÉSULTATS}

Au tableau 2 figurent pour les mâles et les femelles les moyennes arithmétiques et les coefficients de variation exprimés en $p$. Ioo des paramètres étudiés, à la fois pour les animaux normaux et ceux appartenant à chacun des lots expérimentaux définis au tableau I. La première constatation qui s'impose est que, pour les deux sexes, les coefficients de variation du poids vif vide, du muscle, du squelette et du foie sont faibles, presque toujours compris entre o et $I 5$ p. Ioo, et n'excèdent que très rarement $20 \mathrm{p}$. Ioo. Par contre, les glandes étudiées (ovaires, testicules, surrénales et thyroïdes) et le tissu adipeux sont affectés d'un coefficient souvent très élevé. Cette importante variabilité et la petite taille des échantillons n'ont pas permis de faire une analyse statistique rigoureuse et notamment de tester les significations des différences observées. I1 ressort cependant de nombreux enseignements de la comparaison des différents lots expérimentaux avec les agneaux normaux abattus au début et à la fin des périodes étudiées. 
TABLEAU 2

Comparaison des moyennes en grammes et de leurs coefficients de variation en $p$. 100 , entre les animaux des différents lots expérimentaux définis au tableau 1 et les agneaux normaux disséqués au début et à la fin des périodes étudiées

\begin{tabular}{|c|c|c|c|c|c|c|}
\hline \multirow{2}{*}{$\begin{array}{l}\text { Période étudiée } \\
\text { (sexe) }\end{array}$} & \multirow{2}{*}{$\begin{array}{l}\text { Variable } \\
\text { étudiée }\end{array}$} & \multicolumn{5}{|c|}{ Moyennes en grammes (et coefficient de variation en p. 100) } \\
\hline & & $\begin{array}{l}\text { Normaux } \\
\text { à } 25 \mathrm{j}\end{array}$ & Lot 1 & Lot 2 & Lot 3 & $\begin{array}{l}\text { Normaux } \\
\text { à } 100 \mathrm{j}\end{array}$ \\
\hline \multirow{9}{*}{$\begin{array}{r}25 \text { à } 100 \\
\text { (Mâles) }\end{array}$} & Poids vif & $\begin{array}{c}9690 \\
(6,2)\end{array}$ & $\begin{array}{l}12200 \\
(23,2)\end{array}$ & $\begin{array}{l}19300 \\
(13,0)\end{array}$ & $\begin{array}{c}16100 \\
(6,9)\end{array}$ & $\begin{array}{c}24133 \\
(9,8)\end{array}$ \\
\hline & Poids vif vide & $\begin{array}{c}8937 \\
(6,4)\end{array}$ & $\begin{array}{l}10121 \\
(23,8)\end{array}$ & $\begin{array}{l}16058 \\
(6,3)\end{array}$ & $\begin{array}{l}13528 \\
(5,3)\end{array}$ & $\begin{array}{c}19141 \\
(9,3)\end{array}$ \\
\hline & Muscle & $\begin{array}{l}2917 \\
(7,3)\end{array}$ & $\begin{array}{l}2822 \\
(19,9)\end{array}$ & $\begin{array}{l}5142 \\
(10,4)\end{array}$ & $\begin{array}{c}4466 \\
(3,5)\end{array}$ & $\begin{array}{r}6026 \\
(11,1)\end{array}$ \\
\hline & Squelette & $\begin{array}{c}842 \\
(6,4)\end{array}$ & $\begin{array}{c}1019 \\
(3,4)\end{array}$ & $\begin{array}{c}1376 \\
(9,9)\end{array}$ & $\begin{array}{l}1282 \\
(0,2)\end{array}$ & $\begin{array}{l}1553 \\
(13,7)\end{array}$ \\
\hline & Dépôts adipeux & $\begin{array}{c}671 \\
(26,2)\end{array}$ & $\begin{array}{l}1640 \\
(4,0)\end{array}$ & $\begin{array}{c}761 \\
(16,6)\end{array}$ & $\begin{array}{c}207 \\
(57,5)\end{array}$ & $\begin{array}{c}992 \\
(17,8)\end{array}$ \\
\hline & Testicules & $\begin{array}{c}3,57 \\
(33,6)\end{array}$ & $\begin{array}{c}2,60 \\
(35,3)\end{array}$ & $\begin{array}{l}16,56 \\
(35,8)\end{array}$ & $\begin{array}{c}3,98 \\
(31,3)\end{array}$ & $\begin{array}{c}26 \\
(21,5)\end{array}$ \\
\hline & Surrénales & $\begin{array}{c}0,93 \\
(10,8)\end{array}$ & $\begin{array}{r}0,605 \\
(10,5)\end{array}$ & $\begin{array}{l}1,40 \\
(6,3)\end{array}$ & $\begin{array}{c}0,66 \\
(20,3)\end{array}$ & $\begin{array}{r}1,46 \\
(16,1)\end{array}$ \\
\hline & Thyroïde & $\begin{array}{c}1,34 \\
(20,3)\end{array}$ & $\begin{array}{l}0,71 \\
(1,9)\end{array}$ & $\begin{array}{l}1,43 \\
(4,0)\end{array}$ & $\begin{array}{c}1,34 \\
(18,7)\end{array}$ & $\begin{array}{c}2,11 \\
(32,2)\end{array}$ \\
\hline & Foie & $\begin{array}{c}206 \\
(10,4)\end{array}$ & $\begin{array}{c}164 \\
(22,4)\end{array}$ & $\begin{array}{c}368 \\
(9,0)\end{array}$ & $\begin{array}{l}255 \\
(3,6)\end{array}$ & $\begin{array}{r}415 \\
(8,2)\end{array}$ \\
\hline \multirow{9}{*}{$\begin{array}{l}25 \text { à } 100 \text { j } \\
\text { (Femelles) }\end{array}$} & Poids vif & $\begin{array}{l}9462 \\
(2,5)\end{array}$ & $\begin{array}{c}13000 \\
(15)\end{array}$ & $\begin{array}{c}17650 \\
(3,6)\end{array}$ & $\begin{array}{c}17625 \\
(17)\end{array}$ & $\begin{array}{c}23166 \\
(4,5)\end{array}$ \\
\hline & Poids vif vide & $\begin{array}{l}8928 \\
(2,3)\end{array}$ & $\begin{array}{l}11160 \\
(10,6)\end{array}$ & $\begin{array}{c}15032 \\
(0,36)\end{array}$ & $\begin{array}{l}14567 \\
(14,3)\end{array}$ & $\begin{array}{c}18661 \\
(7,3)\end{array}$ \\
\hline & Muscle & $\begin{array}{c}2972 \\
(5)\end{array}$ & $\begin{array}{c}3105 \\
(0,5)\end{array}$ & $\begin{array}{l}4688 \\
(3,15)\end{array}$ & $\begin{array}{r}4678 \\
(17,7)\end{array}$ & $\begin{array}{l}5877 \\
(3,0)\end{array}$ \\
\hline & Squelette & $\begin{array}{c}820 \\
(7,9)\end{array}$ & $\begin{array}{l}1001 \\
(0,4)\end{array}$ & $\begin{array}{l}1257 \\
(3,26)\end{array}$ & $\begin{array}{l}1276 \\
(5,9)\end{array}$ & $\begin{array}{l}1543 \\
(4,1)\end{array}$ \\
\hline & Dépôts adipeux & $\begin{array}{c}690 \\
(5,8)\end{array}$ & $\begin{array}{c}1734 \\
(31)\end{array}$ & $\begin{array}{r}953 \\
(36)\end{array}$ & $\begin{array}{r}684 \\
(48)\end{array}$ & $\begin{array}{l}1637 \\
(9,5)\end{array}$ \\
\hline & Ovaires & $\begin{array}{r}1,05 \\
(28)\end{array}$ & $\begin{array}{c}0,98 \\
(30,8)\end{array}$ & $\begin{array}{c}0,86 \\
(13,8)\end{array}$ & $\begin{array}{l}0,73 \\
(58)\end{array}$ & $\begin{array}{c}1,20 \\
(11,1)\end{array}$ \\
\hline & Surrénales & $\begin{array}{l}0,93 \\
(18)\end{array}$ & $\begin{array}{c}0,71 \\
(22,7)\end{array}$ & $\begin{array}{l}1,12 \\
(2,5)\end{array}$ & $\begin{array}{l}0,84 \\
(16)\end{array}$ & $\begin{array}{c}1,39 \\
(14,4)\end{array}$ \\
\hline & Thyroinde & $\begin{array}{c}1,32 \\
(17)\end{array}$ & $\begin{array}{l}1,09 \\
(1,3)\end{array}$ & $\begin{array}{l}1,72 \\
(14)\end{array}$ & $\begin{array}{l}1,79 \\
(18)\end{array}$ & $\begin{array}{c}1,97 \\
(21,7)\end{array}$ \\
\hline & Foie & $\begin{array}{l}188 \\
(13)\end{array}$ & $\begin{array}{c}161 \\
(9,6)\end{array}$ & $\begin{array}{c}288 \\
(2,4)\end{array}$ & $\begin{array}{l}309 \\
(24)\end{array}$ & $\begin{array}{c}366 \\
(6,8)\end{array}$ \\
\hline
\end{tabular}


A. VÉZINHET

TABLEAU 2 (suite)

\begin{tabular}{|c|c|c|c|c|c|c|}
\hline \multirow{2}{*}{$\begin{array}{l}\text { Periode étudiée } \\
\quad \text { (sexe) }\end{array}$} & \multirow{2}{*}{$\begin{array}{l}\text { Variable } \\
\text { étudiée }\end{array}$} & \multicolumn{5}{|c|}{ Moyennes en grammes (et coefficient de variation en p. 100) } \\
\hline & & $\begin{array}{l}\text { Normaux } \\
\grave{a ̀ ~} 50 \mathrm{j}\end{array}$ & Lot 4 & Lot 5 & Lot 6 & $\begin{array}{l}\text { Normaux } \\
\text { à } 150 \mathrm{j}\end{array}$ \\
\hline \multirow{9}{*}{$\begin{array}{c}50 \text { à } 150 \mathrm{j} \\
\text { (Mâles) }\end{array}$} & Poids vif & $\begin{array}{c}14725 \\
(5,7)\end{array}$ & $\begin{array}{c}16887 \\
(5,2)\end{array}$ & $\begin{array}{c}30150 \\
(4,4)\end{array}$ & $\begin{array}{l}25800 \\
(14,9)\end{array}$ & $\begin{array}{c}29500 \\
(4,0)\end{array}$ \\
\hline & Poids vif vide & $\begin{array}{c}12352 \\
(5,8)\end{array}$ & $\begin{array}{c}13231 \\
(7,0)\end{array}$ & $\begin{array}{c}24078 \\
(8,7)\end{array}$ & $\begin{array}{l}22406 \\
(14,7)\end{array}$ & $\begin{array}{c}23396 \\
(3,7)\end{array}$ \\
\hline & Muscle & $\begin{array}{l}4237 \\
(9,9)\end{array}$ & $\begin{array}{l}3741 \\
(7,1)\end{array}$ & $\begin{array}{l}6997 \\
(9,8)\end{array}$ & $\begin{array}{r}7099 \\
(12,4)\end{array}$ & $\begin{array}{l}7250 \\
(1,4)\end{array}$ \\
\hline & Squelette & $\begin{array}{l}1176 \\
(1,0)\end{array}$ & $\begin{array}{l}1154 \\
(4,9)\end{array}$ & $\begin{array}{l}1867 \\
(3,7)\end{array}$ & $\begin{array}{l}1883 \\
(12,1)\end{array}$ & $\begin{array}{l}1789 \\
(7,7)\end{array}$ \\
\hline & Dépôts adipeux & $\begin{array}{c}698 \\
(41,6)\end{array}$ & $\begin{array}{l}1958 \\
(38,3)\end{array}$ & $\begin{array}{l}1443 \\
(32,4)\end{array}$ & $\begin{array}{c}832 \\
(17,6)\end{array}$ & $\begin{array}{l}1908 \\
(21,0)\end{array}$ \\
\hline & Testicules & $\begin{array}{r}5,07 \\
(14,0)\end{array}$ & $\begin{array}{l}3,57 \\
(5,1)\end{array}$ & $\begin{array}{c}58,75 \\
(82,2)\end{array}$ & $\begin{array}{l}6,48 \\
(36,4)\end{array}$ & $\begin{array}{c}55 \\
(35,1)\end{array}$ \\
\hline & Surrénales & $\begin{array}{c}1,16 \\
(10,8)\end{array}$ & $\begin{array}{c}0,90 \\
(26,2)\end{array}$ & $\begin{array}{c}1,89 \\
(19,4)\end{array}$ & $\begin{array}{c}1,01 \\
(16,3)\end{array}$ & $\begin{array}{l}1,82 \\
(1,9)\end{array}$ \\
\hline & Thyroïde & $\begin{array}{c}1,52 \\
(28,6)\end{array}$ & $\begin{array}{c}1,62 \\
(50,9)\end{array}$ & $\begin{array}{c}2,92 \\
(27,8)\end{array}$ & $\begin{array}{c}3,76 \\
(57,2)\end{array}$ & $\begin{array}{l}1,87 \\
(9,4)\end{array}$ \\
\hline & Foie & $\begin{array}{c}306 \\
(12,7)\end{array}$ & $\begin{array}{c}268 \\
(9,1)\end{array}$ & $\begin{array}{c}549 \\
(0,9)\end{array}$ & $\begin{array}{r}425 \\
(15,1)\end{array}$ & $\begin{array}{c}501 \\
(7,1)\end{array}$ \\
\hline \multirow{9}{*}{$\begin{array}{l}50 \text { a } 150 \mathrm{j} \\
\text { (Femelles) }\end{array}$} & Poids vif & $\begin{array}{c}13625 \\
(4,3)\end{array}$ & $\begin{array}{c}18160 \\
(17)\end{array}$ & $\begin{array}{c}23300 \\
(24,2)\end{array}$ & $\begin{array}{c}19650 \\
(12)\end{array}$ & $\begin{array}{c}26250 \\
(4,0)\end{array}$ \\
\hline & Poids vif vide & $\begin{array}{c}12046 \\
(4,6)\end{array}$ & $\begin{array}{c}14622 \\
(17)\end{array}$ & $\begin{array}{r}19135 \\
(3,36)\end{array}$ & $\begin{array}{l}16521 \\
(12,9)\end{array}$ & $\begin{array}{c}22150 \\
(1,1)\end{array}$ \\
\hline & Muscle & $\begin{array}{r}3800 \\
(5,96)\end{array}$ & $\begin{array}{l}4139 \\
(15,8)\end{array}$ & $\begin{array}{l}5950 \\
(7,0)\end{array}$ & $\begin{array}{l}5383 \\
(8,5)\end{array}$ & $\begin{array}{c}7271 \\
(7,4)\end{array}$ \\
\hline & Squelette & $\begin{array}{l}1019 \\
(5,35)\end{array}$ & $\begin{array}{r}1172 \\
(10,0)\end{array}$ & $\begin{array}{l}1550 \\
(5,1)\end{array}$ & $\begin{array}{l}1366 \\
(7,9)\end{array}$ & $\begin{array}{l}1520 \\
(6,7)\end{array}$ \\
\hline & Dépôts adipeux & $\begin{array}{c}1108 \\
(30)\end{array}$ & $\begin{array}{l}2321 \\
(18,4)\end{array}$ & $\begin{array}{l}1341 \\
(19,7)\end{array}$ & $\begin{array}{c}656 \\
(60,2)\end{array}$ & $\begin{array}{l}2369 \\
(3,9)\end{array}$ \\
\hline & Ovaires & $\begin{array}{r}1,37 \\
(30,7)\end{array}$ & $\begin{array}{c}0,51 \\
(41,9)\end{array}$ & $\begin{array}{c}0,56 \\
(46,3)\end{array}$ & $\begin{array}{c}0,73 \\
(33,8)\end{array}$ & $\begin{array}{c}1,20 \\
(0)\end{array}$ \\
\hline & Surrénales & $\begin{array}{l}1,28 \\
(15)\end{array}$ & $\begin{array}{c}0,79 \\
(14,1)\end{array}$ & $\begin{array}{c}1,40 \\
(10,5)\end{array}$ & $\begin{array}{l}0,84 \\
(8,7)\end{array}$ & $\begin{array}{l}1,31 \\
(2,7)\end{array}$ \\
\hline & Thyroïde & $\begin{array}{c}1,69 \\
(20,5)\end{array}$ & $\begin{array}{c}1,28 \\
(38,6)\end{array}$ & $\begin{array}{c}3,25 \\
(36,9)\end{array}$ & $\begin{array}{c}2,36 \\
(20,9)\end{array}$ & $\begin{array}{r}1,82 \\
(9,6)\end{array}$ \\
\hline & Foie & $\begin{array}{c}252 \\
(6,1)\end{array}$ & $\begin{array}{c}268 \\
(21,3)\end{array}$ & $\begin{array}{c}397 \\
(10,4)\end{array}$ & $\begin{array}{l}318 \\
(15)\end{array}$ & $\begin{array}{l}446 \\
(3,3)\end{array}$ \\
\hline
\end{tabular}


TABLEAU 2 (suite)

\begin{tabular}{|c|c|c|c|c|c|}
\hline \multirow{2}{*}{$\begin{array}{l}\text { Periode étudí́e } \\
\text { (sexe) }\end{array}$} & \multirow{2}{*}{$\begin{array}{l}\text { Variable } \\
\text { étudiée }\end{array}$} & \multicolumn{4}{|c|}{ Moyennes en grammes (et cœfficient de variation en p. 100) } \\
\hline & & $\begin{array}{l}\text { Normaux } \\
\text { à } 100 \mathrm{j}\end{array}$ & Lot 7 & Lot 8 & $\begin{array}{c}\text { Normaux } \\
\text { à } 250 \mathrm{j}\end{array}$ \\
\hline \multirow{9}{*}{$\begin{array}{c}100 \text { à } 250 \mathrm{j} \\
\text { (Mâles) }\end{array}$} & Poids vif & $\begin{array}{c}24133 \\
(9,8)\end{array}$ & $\begin{array}{l}25833 \\
(10,0)\end{array}$ & $\begin{array}{c}43150 \\
(6,7)\end{array}$ & $\begin{array}{c}43400 \\
(2,9)\end{array}$ \\
\hline & Poids vif vide & $\begin{array}{c}19141 \\
(9,3)\end{array}$ & $\begin{array}{c}21818 \\
(8,9)\end{array}$ & $\begin{array}{l}34377 \\
(14,2)\end{array}$ & $\begin{array}{c}35780 \\
(3,4)\end{array}$ \\
\hline & Muscle & $\begin{array}{l}6026 \\
(11,1)\end{array}$ & $\begin{array}{l}6072 \\
(8,5)\end{array}$ & $\begin{array}{c}11211 \\
(12,5)\end{array}$ & $\begin{array}{c}11825 \\
(7,4)\end{array}$ \\
\hline & Squelette & $\begin{array}{l}1553 \\
(13,7)\end{array}$ & $\begin{array}{c}1633 \\
(8,4)\end{array}$ & $\begin{array}{l}2523 \\
(2,0)\end{array}$ & $\begin{array}{c}2645 \\
(3,6)\end{array}$ \\
\hline & Tissus adipeux & $\begin{array}{c}992 \\
(17,8)\end{array}$ & $\begin{array}{l}3717 \\
(14,6)\end{array}$ & $\begin{array}{l}3189 \\
(27,0)\end{array}$ & $\begin{array}{l}3165 \\
(16,2)\end{array}$ \\
\hline & Testicules & $\begin{array}{c}26 \\
(21,5)\end{array}$ & $\begin{array}{c}9,30 \\
(24,7)\end{array}$ & $\begin{array}{c}215 \\
(37,5)\end{array}$ & $\begin{array}{l}215,9 \\
(22,6)\end{array}$ \\
\hline & Surrénales & $\begin{array}{c}1,46 \\
(16,1)\end{array}$ & $\begin{array}{c}0,96 \\
(15,8)\end{array}$ & $\begin{array}{c}2,15 \\
(32,8)\end{array}$ & $\begin{array}{l}1,95 \\
(0)\end{array}$ \\
\hline & Thyroïde & $\begin{array}{c}2,11 \\
(32,2)\end{array}$ & $\begin{array}{c}1,58 \\
(14,9)\end{array}$ & $\begin{array}{c}3,52 \\
(11,0)\end{array}$ & $\begin{array}{c}4,15 \\
(11,9)\end{array}$ \\
\hline & Foie & $\begin{array}{l}415 \\
(8,2)\end{array}$ & $\begin{array}{c}331 \\
(19,3)\end{array}$ & $\begin{array}{r}643 \\
(7,2)\end{array}$ & $\begin{array}{r}620 \\
(3,5)\end{array}$ \\
\hline \multirow{9}{*}{$\begin{array}{l}100 \text { à } 250 \mathrm{j} \\
\text { (Femelles) }\end{array}$} & Poids vif & $\begin{array}{c}23166 \\
(4,5)\end{array}$ & $\begin{array}{l}26350 \\
(20,6)\end{array}$ & $\begin{array}{r}34850 \\
(10,7)\end{array}$ & $\begin{array}{c}31250 \\
(1,1)\end{array}$ \\
\hline & Poids vif vide & $\begin{array}{c}18661 \\
(7,3)\end{array}$ & $\begin{array}{c}22309 \\
(22,8)\end{array}$ & $\begin{array}{c}29590 \\
(12,9)\end{array}$ & $\begin{array}{c}26746 \\
(0,6)\end{array}$ \\
\hline & Muscle & $\begin{array}{l}5877 \\
(3,0)\end{array}$ & $\begin{array}{l}5484 \\
(6,9)\end{array}$ & $\begin{array}{l}8465 \\
(16,2)\end{array}$ & $\begin{array}{l}8486 \\
(4,9)\end{array}$ \\
\hline & Squelette & $\begin{array}{l}1543 \\
(4,1)\end{array}$ & $\begin{array}{l}1479 \\
(7,1)\end{array}$ & $\begin{array}{l}2069 \\
(9,6)\end{array}$ & $\begin{array}{l}1953 \\
(10,2)\end{array}$ \\
\hline & Dépôts adipeux & $\begin{array}{l}1637 \\
(9,5)\end{array}$ & $\begin{array}{l}4027 \\
(39,2)\end{array}$ & $\begin{array}{l}3548 \\
(18,8)\end{array}$ & $\begin{array}{l}2789 \\
(23,0)\end{array}$ \\
\hline & Ovaires & $\begin{array}{c}1,20 \\
(11,1)\end{array}$ & $\begin{array}{c}0,49 \\
(29,9)\end{array}$ & $\begin{array}{l}1,60 \\
(8,3)\end{array}$ & $\begin{array}{c}1,74 \\
(27,6)\end{array}$ \\
\hline & Surrénales & $\begin{array}{c}1,39 \\
(14,4)\end{array}$ & $\begin{array}{c}1,13 \\
(45,4)\end{array}$ & $\begin{array}{c}1,61 \\
(16,1)\end{array}$ & $\begin{array}{c}2,02 \\
(12,2)\end{array}$ \\
\hline & Thyroïde & $\begin{array}{c}1,97 \\
(21,7)\end{array}$ & $\begin{array}{c}1,40 \\
(40,4)\end{array}$ & $\begin{array}{c}3,10 \\
(13,6)\end{array}$ & $\begin{array}{l}2,05 \\
(3,4)\end{array}$ \\
\hline & Foie & $\begin{array}{c}366 \\
(6,8)\end{array}$ & $\begin{array}{c}331 \\
(13,2)\end{array}$ & $\begin{array}{c}440 \\
(1,7)\end{array}$ & $\begin{array}{c}501 \\
(3,8)\end{array}$ \\
\hline
\end{tabular}




\section{A. - Étude de la croissance pondérale}

Le poids vif et le poids vif vide.

Les considérations qui s'imposent sur le développement corporel ont été largement développées dans un article précédent (VÉzINHET et DAUZIER, I970). L'observation des poids vifs et des poids vifs vides nous permet de rappeler que l'hypophysectomie provoque dans tous les cas (lots $I, 4$ et 7) un très fort ralentissement de la croissance pondérale globale. Pour les animaux ayant subi un simulacre d'opération (lots 2, 5 et 8), l'influence du choc opératoire est d'autant plus marquée que celui-ci est plus précoce et que la durée de survie est plus courte. Enfin, pour les animaux hypophysectomisés soumis à un traitement chronique à la BGH (lots 3 et 6), on note une très importante récupération du déficit de poids observé dans le cas des animaux simplement hypophysectomisés.

\section{Le tissu musculaire.}

L'hypophysectomie (lots I, 4 et 7) affecte considérablement l'évolution pondérale de la masse musculaire ; les valeurs obtenues sont très voisines et souvent même inférieures à celles observées chez les animaux normaux abattus au début des trois périodes étudiées.

Pour les animaux des deux sexes ayant subi un simulacre d'opération (lots 2, 5 et 8) le tissu musculaire présente les mêmes caractéristiques que le poids vif vide. Entre 25 jours et Ioo jours le choc opératoire entraîne un déficit en muscle par rapport aux agneaux normaux disséqués à roo jours. Entre 50 et 150 jours la même situation se retrouve, mais les mâles pseudo-opérés se rapprochent ici sensiblement des normaux à 150 jours. Enfin, pour la période de Ioo à 250 jours et pour les deux sexes les valeurs en muscles sont très semblables entre les agneaux pseudo-opérés et les normatix.

Le traitement chronique à la $\mathrm{BGH}$ permet de compenser en grande partie ou même totalement, le déficit en muscles enregistré dans le cas de l'hypophysectomie sans traitement. Entre 25 et roo jours, par rapport aux pseudo-opérés si la masse musculaire des mâles hypophysectomisés traités à la $\mathrm{BGH}$ reste légèrement inférieure, celle des femelles, par contre, est comparable. Entre $5^{\circ}$ et 150 jours, la situation inverse est enregistrée.

\section{Le tissu osseux.}

L'ablation hypophysaire réduit le rythme de développement du squelette, surtout pour la période étudiée entre Ioo et 250 jours (lot 7 ). A $5_{50}$ jours, les femelles hypophysectomisées ont une masse osseuse qui, comparée aux femelles normales de $5^{0}$ jours, semble avoir été l'objet d'un faible développement. Les mâles opérés à 50 jours manifestent, par contre, un arrêt complet de croissance osseuse.

Enfin, pour la période de 25 à roo jours, les animaux des deux sexes (lot 2) ont eu, après hypophysectomie, une croissance de la masse squelettique non négligeable, bien qu'elle reste nettement inférieure à celle des animaux pseudo-opérés ou a fortiori des normaux. Le squelette des agneaux ayant subi un simulacre d'opération n'est pas affecté dans son développement entre 50 et 150 jours (lot 5) et 100 et 
250 jours (lot 8 ). Pour les animaux pseudo-opérés disséqués à roo jours (lot 2 ) et comparés aux normaux du même âge, le choc opératoire perturbe nettement le développement de la masse osseuse.

Pour les hypophysectomisés traités chroniquement à la BGH (lots 3 et 6), dans tous les cas la masse osseuse présente une évolution pondérale qui la rapproche sensiblement de celle enregistrée pour les pseudo-opérés.

\section{Le tissu adipeux.}

Comme nous l'avons déjà signalé, les données pondérales concernant le tissu adipeux (tabl. 2) sont la plupart du temps affectées d'un fort coefficient de variation. Malgré cela, on peut attribuer un sens aux différences qui sont observées en fonction des traitements subis.

Ainsi 1'hypophysectomie se traduit dans tous les cas par un développement important du tissu adipeux (lots $I, 4$ et 7 ). Ce développement n'est cependant pas très différent de celui observé dans le cas d'animaux normaux, pour les stades 25 à Ioo jours et 50 à $I 50$ jours. Une exception, les mâles du lot $I$ montrent un excès en tissu adipeux comparés aux mâles normaux de roo jours.

Pour la période entre roo et 250 jours, tous les animaux du lot 7 ont une surcharge adipeuse par rapport aux normaux disséqués à 250 jours.

La masse adipeuse des animaux ayant subi un simulacre d'opération est fortement perturbée dans sa croissance quand l'intervention est pratiquée à l'âge de 25 jours (lot 2). Les femelles pseudo-opérées entre 50 et I50 jours présentent une diminution importante du poids du tissu adipeux. Les mâles, pour la même période, sont moins affectés. Ėnfin, pour la période de roo à 250 jours la masse adipeuse présente un développement normal chez les pseudo-opérés (lot 8$)$.

Ies agneaux hypophysectomisés traités à la BGH (lots 3 et 6 ), ont toujours des tissus adipeux très faibles, nettement inférieurs à ceux notés pour les animaux normaux du même âge.

\section{Les gonades.}

L'hypophysectomie provoque un arrêt du développement des testicules et induit même dans tous les cas une régression pondérale. Cette régression semble être d'autant plus forte que l'animal est opéré plus tardivement et que la durée de survie est plus longue. Les ovaires subissent également une importante perte de poids qui s'accuse avec l'âge des animaux.

Chez les animaux pseudo-opérés, l'évolution pondérale des testicules est normale ; par contre, le poids des ovaires est inférieur à ceux de femelles normales disséquées à 100, I50 et 250 jours ; mais l'importante variabilité du poids des ovaires ne permet pas de tirer de conclusion certaine.

Le poids des gonades des animaux hypophysectomisés traités à la $\mathrm{BGH}$, est comparable à celui des hypophysectomisés sans traitement.

\section{Les surrénales.}

Les observations faites au sujet des gonades restent valables dans le cas des glandes surrénales. L'hypophysectomie réduit considérablement ou même supprime le développement pondéral des surrénales. Le traitement à la BGH n'a pas ou 
peu d'effet pour corriger l'influence de l'ablation hypophysaire. Chez les animaux pseudo-opérés, la croissance des surrénales reste sensiblement la même que celle observée dans le cas des animaux normaux.

\section{La thyroide.}

Comme pour les gonades et les surrénales, par rapport aux agneaux normaux, 1a thyroide est toujours affectée dans son développement par la suppression de la glande pituitaire.

Les injections répétées deBGH semblent, par contre, avoir un effet sur la thyroïde. Dans tous les cas et par rapport aux hypophysectomisés sans traitement, le poids est augmenté de façon nette (lots 3 et 6).

L'évolution pondérale de la thyroïde des animaux pseudo-opérés n'apporte pas d'indication particulière.

Le foie.

L'hypophysectomie provoque un arrêt complet du développement du foie des animaux hypophysectomisés par rapport aux animaux normaux et ceci quelle que soit la période envisagée (lots I, 4 et 7 ).

Pour les agneaux ayant subi un simulacre d'opération la croissance du foie est peu perturbée. Chez les agneaux hypophysectomisés traités chroniquement à la $\mathrm{BGH}$, dans presque tous les cas envisagés, le poids du foie est très supérieur à celui des animaux hypophysectomisés, et voisin de celui des individus pseudo-opérés, quelquefois même supérieur.

\section{B. - Etude de la croissance relative}

Une étude de 1a croissance relative des différentes variables étudiées devrait aider à mieux définir les évolutions pondérales déjà envisagées dans le paragraphe précédent.

Le tissu musculaire (tab1. 3 et 3 bis, fig. I et I').

La vitesse de croissance spécifique relative de la masse musculaire des hypophysectomisés, en prenant comme variable de référence le poids vif vide de ces animaux, permet de constater une régression pondérale plus importante chez les mâles entre 25 et 100 jours et 50 et 150 jours que chez les femelles : les coefficients d'allométrie $(a)$ sont de $-0,37$ et - I,3I pour les mâles et de 0,20 et 0,42 chez les femelles. Entre Ioo et 250 jours, la vitesse de croissance spécifique relative est plus faible pour les femelles $(a=-0,42)$ que pour les mâles $(a=0,07)$.

Pour les animaux ayant subi un simulacre d'opération, on note une grande similitude de leur croissance relative avec les agneaux normaux.

Enfin, pour les animaux hypophysectomisés traités chroniquement à la BGH, les mâles ont entre 25 etioo jours et 50 et 150 jours des valeurs de $(a)$ de 1,03 et 0,93 contre 0,95 et 0,90 pour les normaux. Pour les femelles, durant les mêmes périodes, les allométries de la masse musculaire sont de 0,92 et $I, I 2$ contre 0,93 et $I, 06$ pour les agnelles normales. 
Le tissu osseux (tab1. 3 et 3 bis, fig. I et I').

La vitesse de croissance spécifique relative du squelette des animaux normaux décroît progressivement de 25 à 250 jours chez les femelles, chez les mâles il y aurait une décroissance entre 25 et 150 jours suivie d'une reprise observée à $25^{\circ}$ jours.

Pour les animaux hypophysectomisés, la croissance relative de l'os est loin d'être arrêtée. De 25 à Ioo jours chez les mâles, le coefficient d'allométrie $(a)$ est de 1,73 et de 0,9 I chez les femelles, ce qui, dans les deux cas, représente une vitesse relative supérieure à celle observée dans le cas des mâles normaux $a=0,80$ et des femelles normales $a=0,86$. La croissance osseuse relative subsiste chez les femelles entre $5^{\circ}$ et 150 jours $(a=0,75)$, tandis que les mâles ont une allométrie négative de $a=-0,33$. Einfin, entre Ioo et $25^{\circ}$ jours la masse osseuse des femelles régresse, $a=-0,26$. Chez les mâles, le coefficient $(a)$ de $0,4 \mathrm{I}$ pendant cette période ne doit pas prêter à confusion. Le gain de masse osseuse de $80 \mathrm{~g}$ enregistré, ne représente que 5, I5 p. roo par rapport au poids initial de l'os des normaux à roo jours, tandis que pendant le même temps les normaux gagnent I $092 \mathrm{~g}$, soit un gain de $70,3 \mathrm{I}$ p. Ioo toujours par rapport aux normaux à roo jours.

Les animaux pseudo-opérés ont des vitesses de croissance spécifiques relatives de l'os très voisines de celles des normaux.

Les hypophysectomisés traités à la BGH ont des coefficients supérieurs à ceux des pseudo-opérés et même des animaux normaux.

Le tissu adipeux (tabl. 3 et 3 bis, fig. I et I').

L'hypophysectomie se traduit dans tous les cas par une très importante surcharge en dépôts adipeux. On relève pour les mâles des coefficients d'allométrie $(a)$ de $8,24,15,3$ et ro,09 pour les trois périodes considérées, valeurs très nettement supérieures à celles des animaux normaux qui sont respectivement pour les mêmes périodes de $0,53, I, 67$ et $I, 85$. Chez les femelles $(a)$ va de 4,07 entre 25 et roo jours à $4, I 4$ entre 50 et I 50 jours et 5 ,I 7 entre roo et 250 jours, les femelles normales ont pour les mêmes périodes des coefficients de $I, I 7, I, 29$ et $I, 44$.

La masse adipeuse dissécable des animaux ayant subi un simulacre d'opération est fortement perturbée dans sa croissance quand le simulacre d'opération est pratiqué à 1'âge de 25 jours, pour les mâles comme pour les femelles. Entre 50 et I 50 jours les femelles présentent une diminution importante de la vitesse de croissance spécifique relative du tissu adipeux. Celle des mâles, par contre, n'est pas affectée. Eñfin, entre roo et 250 jours la masse adipeuse des pseudo-opérés présente un développement normal.

Les agneaux hypophysectomisés traités à laBGH ont, dans trois cas sur quatre, des coefficients d'allométrie $(a)$ négatifs. Seul les mâles hypophysectomisés à 50 jours et abattus à 150 jours présentent un très faible accroissement de la masse adipeuse.

Les gonades (tabl. 3 et 3 bis, fig. 2 et $2^{\prime}$ ).

Les testicules des individus normaux ont toujours une allométrie fortement majorante avec un coefficient (a) de l'ordre de 3 . Chez les hypophysectomisés le coefficient (a) est toujours négatif, ceci d'autant plus que l'animal est opéré tardivement et que la durée de survie est longue. Pour les animaux opérés à 25 , à 50 puis à roo jours (a) passe respectivement de $-2,07$ à $-5,05$ et $-7,85$. Les mêmes conclusions s'impo- 
Mâles: Vitesses de croissance spécifiques ve

\begin{tabular}{|c|c|c|c|c|c|c|c|c|c|c|c|}
\hline Période & Lot & \multicolumn{7}{|c|}{25 à 100 jours } & \multirow{2}{*}{$\begin{array}{l}\text { Lot } \\
\text { exp. }\end{array}$} & & \\
\hline $\begin{array}{c}\text { Variable } \\
\text { étudiée }\left(\mathrm{X}_{i}\right)\end{array}$ & & $\mathrm{X}_{3}$ & $\mathrm{X}_{4}$ & $\mathrm{X}_{5}$ & $\mathrm{X}_{6}$ & $X_{7}$ & $X_{8}$ & $\mathrm{X}_{9}$ & & $\mathrm{x}_{3}$ & $X_{4}$ \\
\hline $\begin{array}{l}\text { Agneaux } \\
\text { normaux }\end{array}$ & $\mathrm{T}$ & 0,95 & 0,80 & 0,53 & 2,75 & 0,59 & 0,57 & 0,92 & $\mathrm{~T}$ & 0,90 & 0,65 \\
\hline $\begin{array}{c}\text { Agneaux } \\
\text { hypophysec- } \\
\text { tomisés }\end{array}$ & Lot 1 & $-0,37$ & 1,73 & 8,24 & $-2,07$ & $-3,84$ & $-5,61$ & $-2,14$ & Lot 4 & $-1,31$ & $-0,33$ \\
\hline $\begin{array}{c}\text { Agneaux } \\
\text { pseudo- } \\
\text { hypophysec- } \\
\text { tomises }\end{array}$ & Lot 2 & 0,96 & 0,84 & 0,24 & 2,75 & 0,71 & 0,13 & 0,99 & Lot 5 & 0,80 & 0,69 \\
\hline $\begin{array}{c}\text { Agneaux } \\
\text { hypophysec- } \\
\text { tornisés } \\
+\mathrm{BGH}\end{array}$ & Lot 3 & 1,03 & 1,01 & $-3,11$ & 0,47 & $-0,85$ & 0,00 & 0,52 & Lot 6 & 0,93 & 0,78 \\
\hline Variables & étudiées & $\left(\mathrm{X}_{i}\right)$ & $\begin{array}{l}\mathrm{X}_{3}= \\
\mathrm{X}_{4}= \\
\mathrm{X}_{5}=\end{array}$ & $\begin{array}{l}\text { Tissu m } \\
\text { Tissu os } \\
\text { Tissu ad }\end{array}$ & $\begin{array}{l}\text { iusculaire } \\
\text { sseux } \\
\text { dipeux }\end{array}$ & & $\begin{array}{l}=\text { Testi } \\
=\text { Surr } \\
=\text { Thyr }\end{array}$ & $\begin{array}{l}\text { cules } \\
\text { nales } \\
\text { oide }\end{array}$ & $\mathbf{x}_{9}=$ & oie. & \\
\hline
\end{tabular}

TAB

Femelles : Vitesses de croissance spécifiques re

\begin{tabular}{|c|c|c|c|c|c|c|c|c|c|c|c|}
\hline $\begin{array}{l}\text { Période } \\
\text { etudiée }\end{array}$ & $\begin{array}{l}\text { Lot } \\
\text { exp. }\end{array}$ & \multicolumn{7}{|c|}{25 à 100 jours } & \multirow[t]{2}{*}{$\begin{array}{l}\text { Lot } \\
\text { exp. }\end{array}$} & \multirow[b]{2}{*}{$\mathrm{X}_{\mathbf{3}}$} & \multirow[b]{2}{*}{$\mathrm{X}_{4}$} \\
\hline $\begin{array}{c}\text { Variable } \\
\text { étudiée }\left(\mathrm{X}_{i}\right)\end{array}$ & & $\mathrm{X}_{3}$ & $X_{4}$ & $X_{5}$ & $X_{6}$ & $x_{7}$ & $x_{8}$ & $X_{9}$ & & & \\
\hline $\begin{array}{c}\text { Agneaux } \\
\text { normaux }\end{array}$ & $\mathrm{T}$ & 0,93 & 0,86 & 1,17 & 0,16 & 0,56 & 0,54 & 0,91 & $\mathbf{T}$ & 1,06 & 0,66 \\
\hline $\begin{array}{c}\text { Agneaux } \\
\text { hypophysec- } \\
\text { tomisés }\end{array}$ & Lot 1 & 0,20 & 0,91 & 4,07 & $-0,48$ & $-1,18$ & $-0,81$ & $-0,68$ & Lot 4 & 0,42 & 0,75 \\
\hline $\begin{array}{l}\text { Agneaux } \\
\text { pseudo- } \\
\text { hypophysec- } \\
\text { tomisés }\end{array}$ & Lot 2 & 0,87 & 0,82 & 0,56 & $-0, \mathbf{1} 1$ & 0,39 & 0,53 & 0,83 & Lot 5 & 0,97 & 0,91 \\
\hline $\begin{array}{c}\text { Agneaux } \\
\text { hypophysec- } \\
\text { tomisés } \\
+\mathrm{BGH}\end{array}$ & Lot 3 & 0,92 & 0,92 & $-0,18$ & $-1,05$ & $-0,20$ & 0,63 & 1,00 & Lot 6 & 1,12 & 0,94 \\
\hline Variables & étudiées & $\left(X_{i}\right)$ & $\begin{array}{l}X_{3} \\
X_{4} \\
X^{5}\end{array}$ & $\begin{array}{l}\text { Tissu } \\
\text { Tissu } \\
\text { Tissu }\end{array}$ & $\begin{array}{l}\text { lusculaire } \\
\text { sseux } \\
\text { dipeux }\end{array}$ & & $\begin{array}{l}=\text { Ova } \\
=\text { Surr } \\
=\text { Thy }\end{array}$ & $\begin{array}{l}\text { res } \\
\text { énales } \\
\text { coïde }\end{array}$ & $X_{9}=$ & Foie. & \\
\hline
\end{tabular}




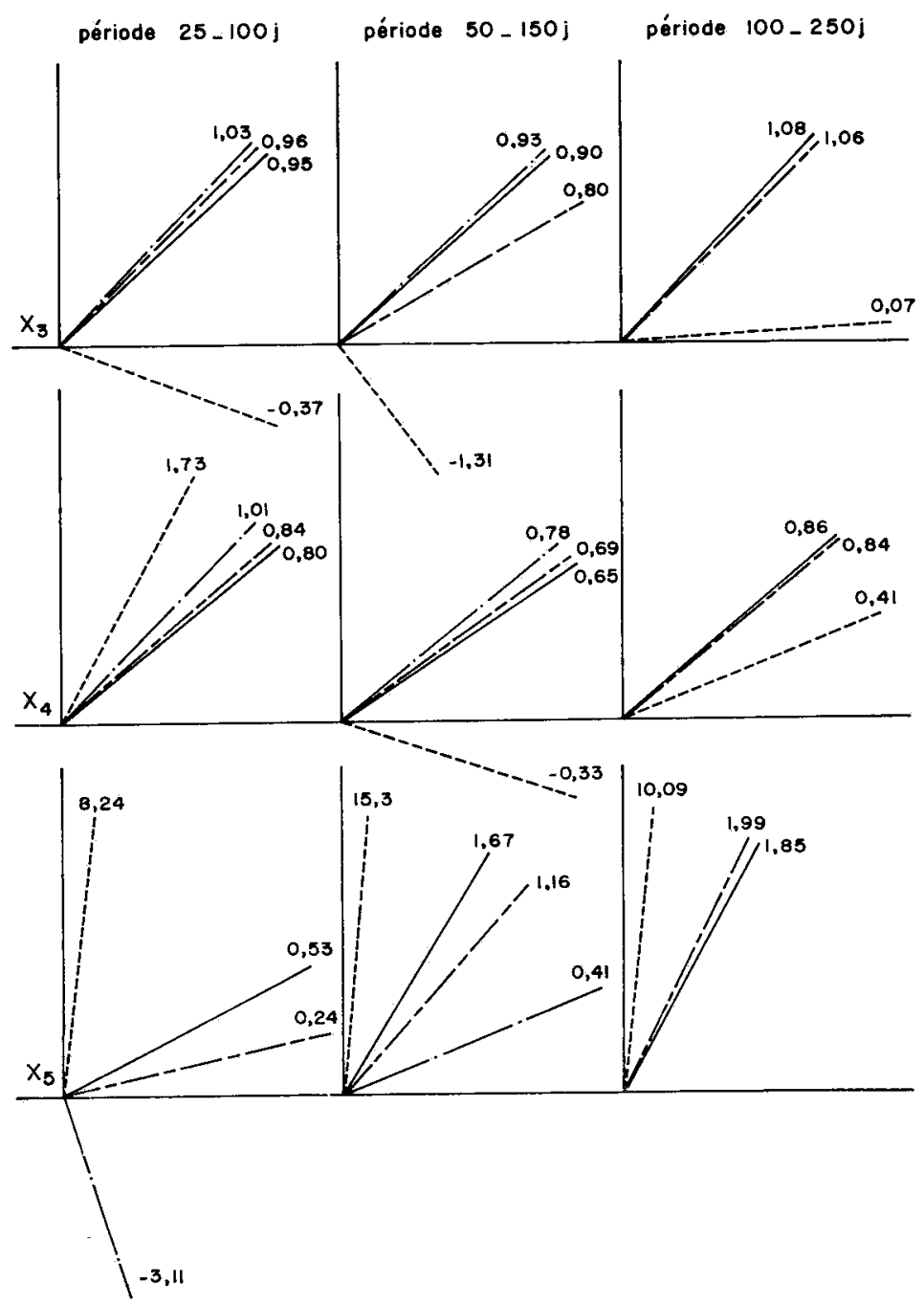

FIG. I. - Variations chez les mâles des coefficients d'allométrie exprimant pour les caractères étudiés $\left(\mathrm{X}_{i}\right)$ les vitesses de croissance spécifiques relatives en fonction des traitements et des périodes considerés

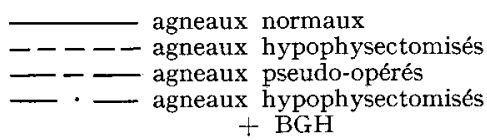

$\mathrm{X}_{3}=$ Tissu musculaire

$\mathrm{X}_{4}=$ Tissu osseux

$\mathrm{X}_{\mathrm{s}}=$ Tissu adipeux 


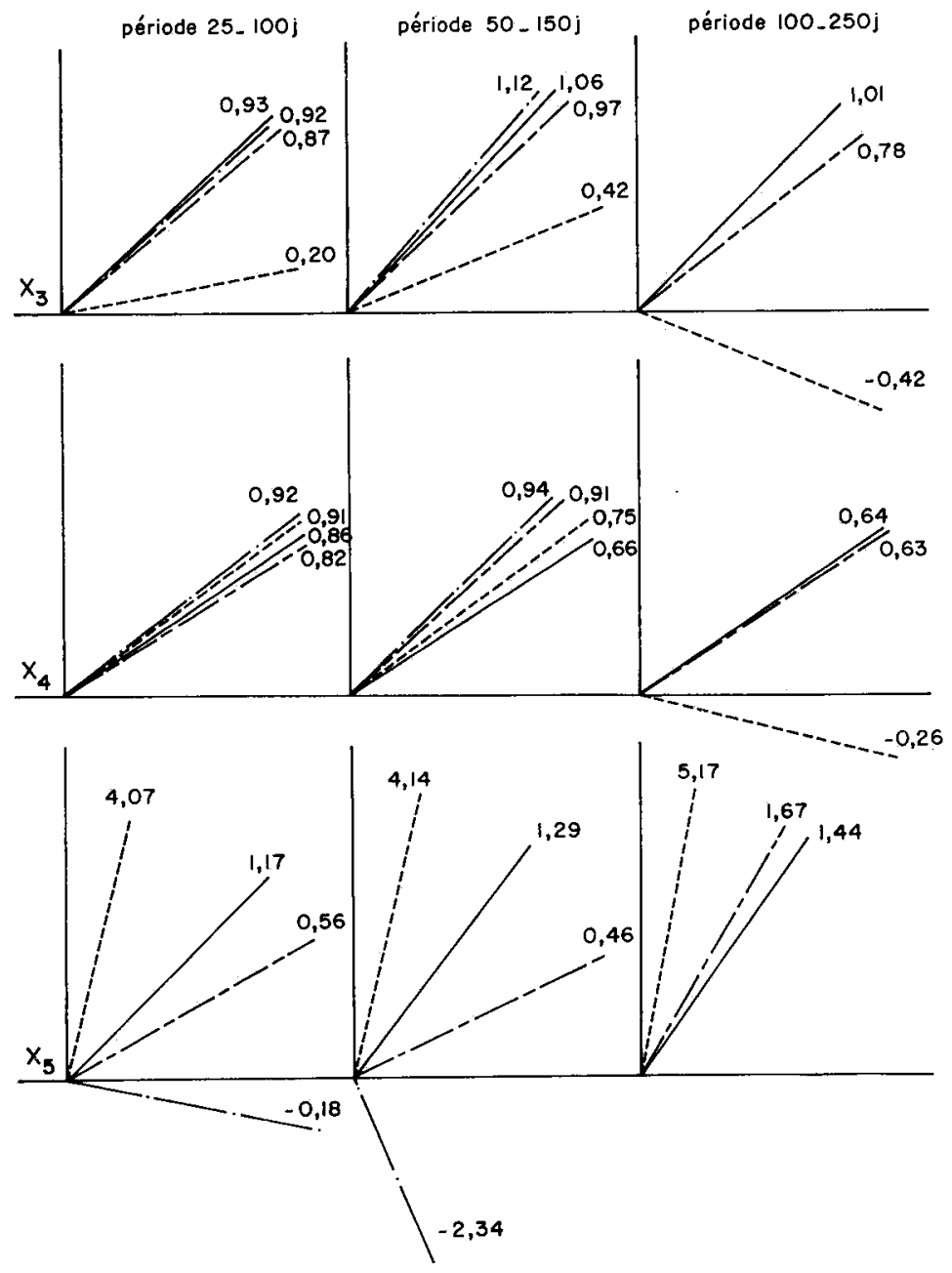

FIG. I'. - Variations chez les femelles des coefficients d'allométrie exprimant pour les caractères étudiés $\left(\mathrm{X}_{\mathbf{i}}\right)$ les vitesses de croissance spécifiques relatives en fonction des traitements et des périodes considérés

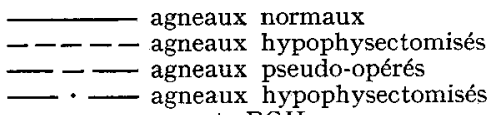

$$
\begin{aligned}
& \mathrm{X}_{3}=\text { Tissu musculaire } \\
& \mathrm{X}_{4}=\text { Tissu osseux } \\
& \mathrm{X}_{5}=\text { Tissu adipeux }
\end{aligned}
$$
$+\mathrm{BGH}$ 


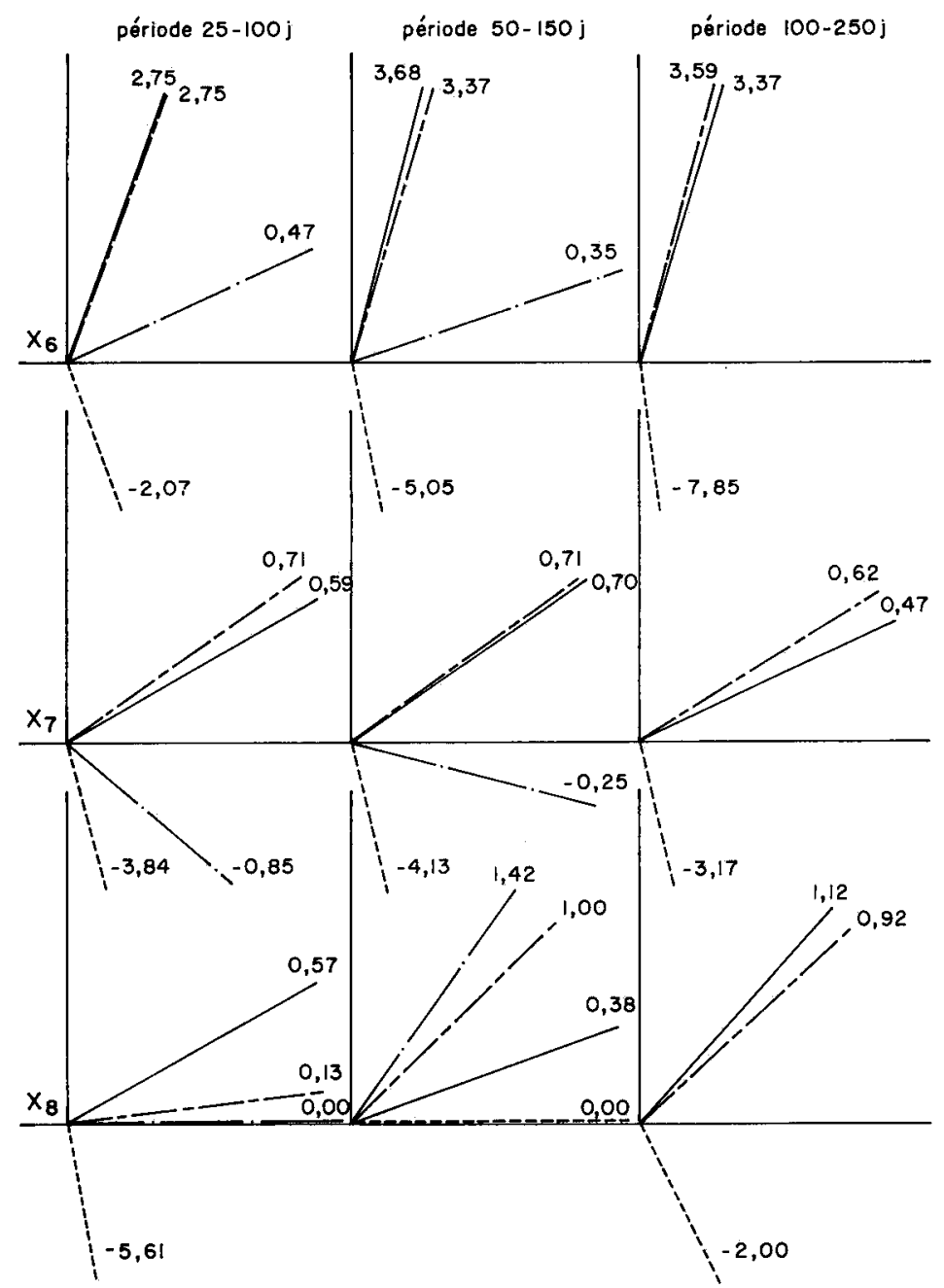

FIG. 2. - Variations chez les mâles des coefficients d'allométrie exprimant pour les caractères étudiés (X:) les vitesses de croissance spécifiques relatives en fonction des traitements et des périodes considérés

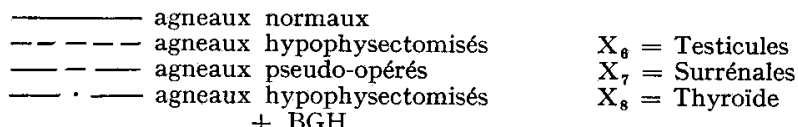

$$
+ \text { BGH }
$$




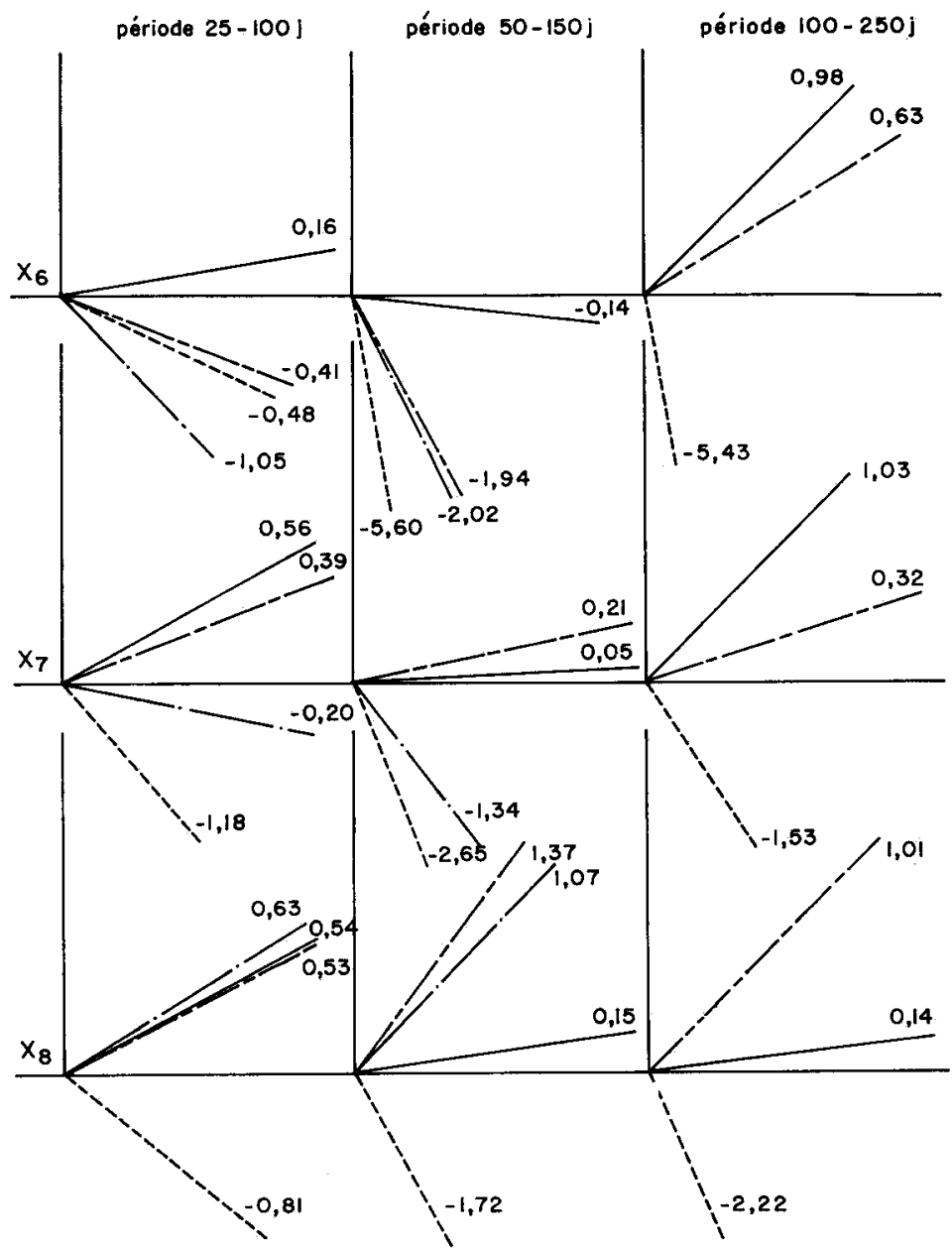

FIG. 2'. - Variations chez les femelles des coefficients d'allométrie exprimant pour les caractères étudiés $\left(\mathrm{X}_{i}\right)$ les vitesses de croissance spécifiques relatives en fonction des traitements et des périodes considérés

- agneaux normaux

- - - agneaux hypophysectomisés

_ - _ agneaux pseudo-opérés

_ـ - agneaux hypophysectomisés $+\mathrm{BGH}$

$$
\begin{aligned}
& \mathrm{X}_{6}=\text { Ovaires } \\
& \mathrm{X}_{7}=\text { Surrénales } \\
& \mathrm{X}_{8}=\text { Thyroïde }
\end{aligned}
$$




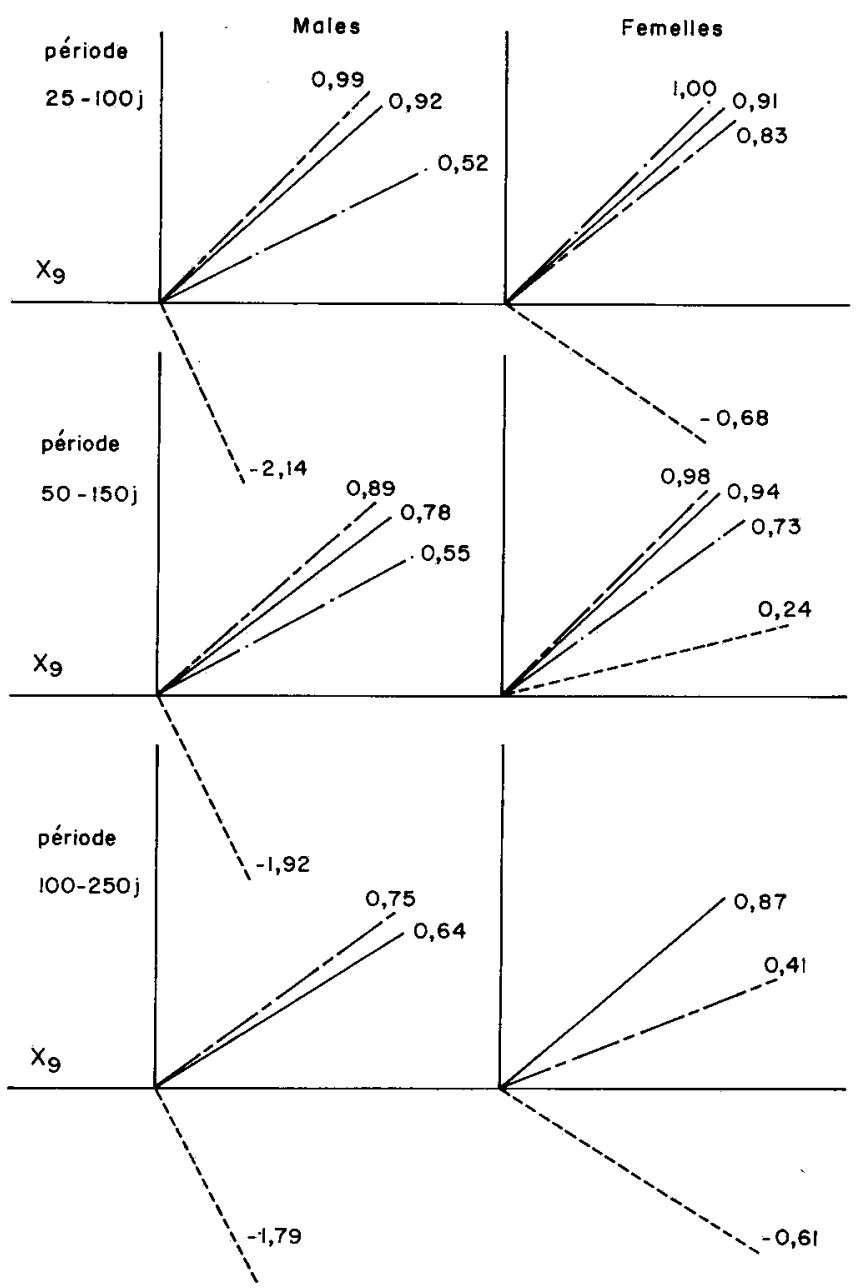

FIG. 3. - Variations chez les mâles et les femelles des coefficients d'allométrie exprimant pour le foie $\left(\mathrm{X}_{\mathrm{g}}\right)$ les vitesses de croissance spécifiques relatives en fonction des traitements et des périodes considérés.

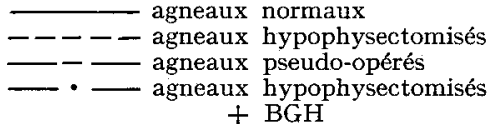


sent au sujet des ovaires pour lesquels $(a)$ prend des valeurs successives de $-0,48$ puis $-5,60$ et $-5,43$.

Pour les hypophysectomisés traités à la BGH, chez les mâles dans tous les cas les coefficients d'allométrie des testicules sont très nettement inférieurs à ceux des animaux normaux ou des témoins ayant subi un simulacre d'opération. Chez les femelles, les ovaires ont des coefficients d'allométrie toujours négatifs.

Les surrénales (tabl. 3 et 3 bis, fig. 2 et $2^{\prime}$ ).

Comme pour la croissance pondérale, l'étude allométrique montre que les observations faites à propos des gonades restent valables dans le cas des glandes surrénales.

La thyroide (tabl. 3 et 3 bis, fig. 2 et $2^{\prime}$ ).

La thyroïde voit sa croissance relative arrêtée par l'ablation hypophysaire; les injections de $\mathrm{BGH}$ font augmenter le coefficient d'allométrie de façon nette dans tous les cas. La croissance relative de la thyroïde des animaux pseudo-opérés ne présente pas d'intérêt particulier.

Le foie (tabl. 3 et 3 bis, fig. 3 ).

Les animaux normaux ont une vitesse de croissance spécifique relative qui varie peu entre 25 et 250 jours, bien que chez le mâle on note une tendance au ralentissement de cette vitesse. L'hypophysectomie se traduit par des coefficients d'allométrie négatifs. Seules les femelles hypophysectomisées à 50 jours ont un coefficient légèrement positif.

Pour les agneaux pseudo-opérés la croissance relative du foie n'apporte pas d'enseignement particulier. Enfin, les hypophysectomisés traités à la BGH présentent des coefficients d'allométrie très supérieurs à ceux des hypophysectomisés non traités.

\section{DISCUSSION}

Les résultats exposés confirment l'importance du contrôle hypophysaire et plus particulièrement de 1'hormone somatotrope sur la croissance pondérale globale, et sur la croissance relative.

Pour les principaux tissus étudiés, nous constatons que l'hypophysectomie et le traitement chronique à la BGH ont des effets. Le tissu nerveux qui n'a pas été envisagé, ne subit que très peu de variation quel que soit le traitement ; ceci peut être facilement expliqué si l'on considère qu'à la naissance ce tissu a déjà atteint un état de développement presque optimum (HAMmOND 1932). BÉNÉVENT (197I) dans une étude sur la croissance relative de 1'Agneau Mérinos d'Arles a montré que le cerveau se caractérise dans une phase immédiatement postnatale par un coefficient d'allométrie faible, de l'ordre de 0,20 . Le problème de la peau aurait été intéressant à aborder dans le cadre de cette étude ; cependant, les dissections des animaux ayant été réalisées à des périodes très différentes de l'année, il n'a pas été possible de comparer les données obtenues avec la peau d'animaux dont certains étaient tondus, d'autres non.

Avant d'aborder la discussion de l'effet des traitements, nous signalerons que les allométries observées chez les agneaux normaux qui nous servent de référence 
sont toujours du même ordre que celles notées par BÉNÉVENT (I97r). Une exception cependant, le foie pour lequel cet auteur trouve un coefficient d'allométrie supérieur à $I$, alors que celui que nous avons enregistré est toujours inférieur à l'unité.

Pour le tissu musculaire nos résultats viennent confirmer des données déjà très anciennes comme celles de LEE et AYRES (I936) obtenues chez le Rat. L'hormone (BGH) est capable d'assurer un maintien important de la croissance du muscle chez 1'Agneau hypophysectomisé. Là encore de très anciens travaux, réalisés d'abord avec des extraits hypophysaires bruts, comme ceux de SCHAFFER et LEE (I935) 1'ont montré chez le Rat. Young (I945) a, en utilisant des extraits hypophysaires partiellement purifiés, noté une rétention azotée importante chez le Chien, le Chat et le Rat. Enfin, Ir et Evans (I948,) GREENBaum et Young (I953), Scow, (I959) utilisant chez le Rat une GH purifiée ont mis l'accent sur le rôle anabolisant protéique de cette hormone.

En ce qui concerne le tissu osseux, le contrôle hypophysaire de sa croissance n'est pas aussi strict qu'il l'est pour le muscle. Chez le mâle, il subsiste entre 25 et Ioo jours une croissance osseuse non négligeable après hypophysectomie. Chez la femelle le développement de la masse osseuse se poursuit, bien qu'à un degré moindre, à la fois pour la période 25 à Ioo jours et 50 à I50 jours. Ce n'est que durant la période Ioo à $25^{\circ}$ jours que la croissance osseuse est totalement arrêtée dans les deux sexes après hypophysectomie. WALKER et al. (I950) ont remarqué que chez le Rat, un certain développement de 1'os s'opère en absence d'hypophyse jusqu'à un âge d'environ 28 jours. Nous avons pour notre part déjà montré, chez le Lapin, qu'il faut atteindre un âge de roo jours pour constater après hypophysectomie un arrêt de la croissance pondérale globale (VÉzinhes, I968 b). Chez le Cobaye, MrTchel et al. (I954) et KNOBI, et GREEP (I959) ont montré que 1'hypophysectomie n'affectait pas le développement corporel.

L,e traitement GH permet de rétablir une vitesse de croissance osseuse proche de la normale et quelquefois même supérieure chez l'Agneau hypophysectomisé. Cette notion est en accord avec les travaux déjà anciens de Evans et al. (r94 3), BECKS et al. (I949), AsLING et al. (I965) réalisés sur le Rat. Les modalités d'application du traitement pour l'obtention d'un effet optimum de la GH sont encore de nos jours discutées (HANSSON et THORNGREN I97I), mais il ne fait plus de doute que 1'hormone somatotrope exerce un effet sur le développement osseux de la presque totalité des espèces

En ce qui concerne le tissu adipeux, les agneaux hypophysoprives ont une carcasse particulièrement chargée en lipides, ceci d'autant plus que l'âge de l'hypophysectomie est plus tardif et que la durée de survie est plus longue. Le traitement à la $\mathrm{BGH}$ se traduit par une diminution considérable des réserves adipeuses. Ces constatations sont en accord avec ce que l'on sait depuis longtemps sur la surcharge adipeuse des carcasses d'animaux hypophysectomisés et sur l'activité lipolytique de 1'hormone de croissance (Li et al., I948; GREENBAUM, I953 de Bodo et AITSzULLER, r957). Nous avons nous-même pu constater l'effet lipolytique de la BGH chez 1'Agneau qui se traduit par une importante libération d'acides gras libres, dans le sang, depuis les tissus adipeux de réserve (travaux non publiés).

Les observations faites dans ce travail sur les glandes endocrines après hypophysectomie et traitement chronique à l'hormone somatotrope viennent renforcer ce que l'on sait sur les interdépendances entre certaines glandes et 1'hypophyse, 
SIMPSON et al. (I959), SAITER et al. (I957) chez le Rat, LostroH et Lr (I957) chez la Souris, CAMPELI et al. (I959) chez le Chien. Pour ce qui est du testicule, qui montre une allométrie nettement accrue par le traitement à la $\mathrm{BGH}$, cela pourrait s'expliquer par le seul effet de l'hormone sur la trame protéique de cette glande.

A ce sujet, Courot (I97I) signale que l'hormone de croissance administrée en traitement de longue durée est sans effet sur le développement pondéral du testicule de l'Agneau impubère hypophysectomisé, et que seules les hormones gonadotropes sont concernées. On peut alors penser que la présence de contaminants gonadotropes dans la préparation de $\mathrm{GH}$ utilisée ont pu avoir un effet. Pour la thyroïde, l'accroissement de l'allométrie de cette glande chez les animaux traités BGH par rapport aux hypophysectomisés pourrait également être le fait d'une contamination par la TSH de la BGH ayant servi aux traitements. Le thymus a également été étudié et a fait l'objet d'une publication séparée (VÉzINHET, I969).

Enfin, parmi les très nombreuses données fournies par cette étude, nous avons retenu l'exemple du foie pour lequel les évolutions observées dans le cadre des différents traitements traduisent assez fidèlement ce que l'on observe au niveau de l'organisme entier. Ce résultat est en accord avec ceux de Simpson et al. (I949), PeGG et KORNER (I965).

Un dernier point mérite d'être discuté ici, il concerne les aspects nutritionnels. Tous les animaux de cette étude étaient nourris ad libitum. Des contrôles de prise d'aliment entre 50 et I50 jours nous ont montré (tab1. 4) que les animaux sans hypophyse consommaient en moyenne une quantité de concentré inférieure de $28 \mathrm{p}$. I00 à celle ingérée par les agneaux normaux, diminution du même ordre que celle observée chez le Rat par HANn et al. (I965). Pour le foin, cette proportion passait à 66 p. roo. L'important déficit en ingestion de ce dernier aliment peut s'expliquer par l'appétibilité bien supérieure du concentré par rapport au foin. Les indices de consommation de $\mathrm{I} 6$ pour le concentré et de 6 pour le foin tendent à prouver que malgré une prise d'aliment bien inférieure des hypophysectomisés par rapport aux normaux, cela ne peut en aucun cas expliquer toutes les différences enregistrées entre ces deux types d'animaux.

\section{TABLEAU 4}

Comparaison des consommations quotidiennes, et des indices de consommation d'agneaux normaux et hypophysectomisés

\begin{tabular}{|c|c|c|c|c|}
\hline \multirow{2}{*}{$\begin{array}{l}\text { Nature de } \\
\text { l'aliment }\end{array}$} & \multicolumn{2}{|c|}{ Consommation en $\mathrm{g} /$ jour } & \multicolumn{2}{|c|}{$\begin{array}{l}\text { Indice de consommation } \\
\mathrm{kg} \text { aliments } / \mathrm{kg} \text { de croît }\end{array}$} \\
\hline & $\begin{array}{l}\text { Hypophy- } \\
\text { sectomisés }\end{array}$ & Normaux & $\begin{array}{l}\text { Hypophy- } \\
\text { sectomisés }\end{array}$ & Normaux \\
\hline $\begin{array}{l}\text { Aliment } \\
\text { concentré }\end{array}$ & $n^{*}=88$ & $\begin{array}{c}480 \\
n=68\end{array}$ & 16 & 3,2 \\
\hline $\begin{array}{l}\text { Aliment } \\
\text { foin }\end{array}$ & $\begin{array}{c}128 \\
n=88\end{array}$ & $\begin{array}{c}380 \\
n=68\end{array}$ & 6 & 2,5 \\
\hline
\end{tabular}

* $n=$ Nombre d'observations. 
On peut penser que même si les hypophysectomisés consommaient autant d'aliment que les normaux, ils se trouveraient dans l'impossibilité d'en faire une utilisation métabolique rentable. Les hypophysectomisés sont, en outre, capables de synthétiser d'importantes réserves en tissu adipeux, alors que la dénutrition se caractérise par une diminution considérable des réserves lipidiques. On doit alors admettre que l'aspect nutritionnel ne peut expliquer les bouleversements observés tant au niveau de la croissance globale que de la croissance relative.

Reçu pour publication en juin 1972.

\section{SUMMARY}

EFFECT OF HYPOPHYSECTOMY AND BOVINE SOMATOTROPIC HORMONE TREATMENT ON THE RELATIVE GROWTH OF LAMBS

A study of relative growth shows that hypophysectomizing 25, 50, and Ioo-day old lambs stops development of the muscle mass, while the bone tissue continues to develop slightly. The adipose tissue of animals operated at 25-50 days continues to grow without being affected, while the adipose mass growth is stimulated in animals operated at roo days.

When bovine somatotropic hormone (BGH) is injected three times a week at a dose of $3 \mathrm{mg}$ per $\mathrm{kg}$ of live weight, muscle and bone growth is stimulated and the adipose tissue reserves are considerably reduced.

A study of the endocrine glands shows that hypophysectomy causes ponderal regression of the gonads, adrenals, and thyroid. Chronic BGH treatment does not annul the effects observed on the gonads and the adrenals. The thyroid reacts differently.

The liver responds to hypophysectomy and BGH treatment in a way very similar to that of the entire organism.

\section{RÉFÉRENCES BIBLIOGRAPHIQUES}

Asling C. W., Simpson M. E., Evans H. M., r965. Gigantism : its induction by growth hormone in the skeleton of intact and hypophysectomized rats, and its failure following thyroidectomy. Revue suisse Zool., 72, I-33.

Becks H., Asling C. W., Simpson M. E., Li C. H., Evans H. M., I949. The growth of hypophysectomized female rats following chronic treatment with pure pituitary growth hormone. III. Skeletal changes. Growth., 18, I75-I89.

BÉnt́vent M., r968. Guide pour la dissection et l'identification des principaux muscles de la carcasse chez le Mouton. Ann. Biol. anim. Biochim. Biophys., 8, 107-139.

BEnḱvent M., I97r. Croissance relative pondérale postnatale, dans les deux sexes, des principaux tissus et organes de l'Agneau Mérinos d'Arles. Ann. Biol. anim. Biochim. Biophys., 11, 5-39.

DE Bodo R. C., Altszuller N., I957. The metabolic effects of growth hormone and their physiological significance. Vitams. Horm., 15, 205-258.

Campbell J., Chaikof L., Wrenshall G. A., Zemel R., I959. Effect of growth hormone on metabolic and endocrine factors in hypophysectomized dogs. Can.J. Biochem. Physiol., 37, I3I3-1327.

Courot M., i97r. Etablissement de la spermatogenèse chez l'Agneau. Thèse Dr. Sci. nat. Paris, 200 p.

Engel H. R., Hallman L., Sregel S., Bergenstal D., r958, Effect of growth hormone on plasma unesterified fatty acid level of hypophysectomized rats. Proc. Soc. exp. Biol. Med., 98, 753.

Evans H. M., Simpson M. E., Marx W., Kibrick E. A., I943. Bioassay of the pituitary growth hormone wid h of the proximal epiphysial cartilage of the tibia in hypophysectomized rats. Endocrinology, 32, 13-16.

FISHER R. A., I92I. Some remarks on the methods formulated in a recent article on " the quantitative analysis of plant growth. "Ann. Appl. Biol., \%, 367-372.

Greenbaum A. L., 1953. Changes in body composition and respiratory quotient of adult female rats treated with purified growth hormone. Biochem. J., 54; 400-407. 
Greenbaum A. L., Young F. G., 1953. A comparison of the differences in the total nitrogen content of the muscles of the rat, resulting from treatment with growth hormone and from inanition. $J$. Endocr., 9, I27-I35.

HaHn D. W., Ishibashi T., Turner C. W., 1965. Effect of hypophysectomy on feed intake in rats. Proc. Soc. exp., Biol. Med., 119, r238-г24I.

Hammond J., r932. Growth and development of mutton qualities in the sheep., 599 pp., Oliver and Boyd, Edinburgh.

Hansson L. I., Thorngren K. G., 197I in : Menczel J., Harrel A., Calcified tissue structural, functional and metabolic aspects. 45., Academic Press. New York.

Huxley J. S., r932. Problems of relative growth., 276 pp., Methuen, Londres.

Knobil E., GreeP R. O., 1959. The physiology of growth hormone with particular references to its action in the rhesus Monkey and the "species specificity " problem. Recent. Prog. Horm. Res., 15, I-69.

Lee M., Ayres G. B., 1936. The composition of weight lost and the nitrogen partition of tissue in rats after hypophysectomy. Endocrinology, 20, 489-495.

Li C. H., Evans H. M., 1948. The biochemistry of pituitary growth hormone. Recent. Prog. Horm. Res., 3, 3-44.

Ir C. H., Simpson M. E., Evans H. M., 1948. The gigantism produced in normal rats by injection of pituitary growth hormone. III. Main chemical components of the body. Growth., 12, 39-42.

Lostron A. J., LI C. H., 1958. Effect of growth hormone and thyroxine on body weight of hypophysectomized $\mathrm{C}_{3} \mathrm{H}$ mice. Endocrinology, 62, 484-492.

Mitchell M. L., Guillemin R., Selye H., I954. The effect of somatotrophic hormone on the growth of normal and hypophysectomized guinea pigs. Endocrinology, 54, III-II4.

Pegg A. E., Korner A., I965. Growth hormone action on rat liver RNA polymerase. Nature, 205, 904-905.

RABEN M. S., Hollenberg C. H., 1958. Effect of growth hormone on fatty acids. J. Clin. Invest., 87, 922.

Russel J. A., 1955, in : Smith R. W., GAEBler O. H,, Hypophyseal growth hormone nature and actions, 26I, Mc Graw Hill, New York.

Salter J. M., Davidson I. W. F., Best C. H., I957. The effects of insulin and somatotrophin on the growth of hypophysectomized rats. Can. J. Biochem. Physiol., 35, 913-922.

SchafFer N. K., LEE M. O., I935. The effect of the anterior pituitary growth hormone on protein metabolism. J. biol. Chem., 108, 355-37I.

Scow R. O., r959. Effect of growth hormone and thyroxine on growth and chemical composition of muscle, bone and other tissues in thyroidectomized-hypophysectomized rats. Am. J.Physiol., 196, 859865 .

Simpson M. E., Evans H. M., LI C. H., r949. The growth of hypophysectomized female rats following chronic treatment with pure pituitary growth hormone. I. General growth and organ changes. Growth., 13, I5I-I70.

Szego C. M., White A., I949. The influence of growth hormone on fasting metabolism. Endocrino$\log y, 44, \mathrm{I} 50-166$.

Terssier G., I934. Disharmonies et discontinuités dans la croissance. Actualités scientifiques et indus trielles, $n^{\circ} 95$, Hermann, Paris, p. 39.

Vézinhet A., 1968 a. Effet de l'hypophysectomie sur la croissance pondérale de l'Agneau. C. R. Acad. Sci., 266, 388-39o.

VÉzinhet A., I968 b. Effet de l'hypophysectomie sur la croissance pondérale du Lapin. C. R, Acad. Sci., 266, 2348-235r.

Vézinhet A., 1969. Effets de l'hypophysectomie et d'un traitement chronique à l'hormone somatotrope sur l'évolution pondérale du thymus de l'Agneau. C. R. Soc. Biol., 163, 2387-239o.

VEzinhet A., DAUZier L., 1970. Influence de traitements à l'hormone somatotrope bovine sur la croissance pondérale d'agneaux normaux ou hypophysectomisés. Ann. Biol. anim. Biochim. Biophys., 10, 5-I3.

Walker D. G., Simpson M. E., Asling C. N., Evans H. M., I95o. Growth and differenciation in the rat following hypophysectomy at 6 days of age. Anat. Rec., 108, 539-554.

Young F. G., I945. Growth and diabetes in normal animals treated with pituitary (anterior lobe) diabetogenic extracts. Biochem. J., 39, 515-536. 